Article

\title{
Prediction of Reformed Gas Composition for Diesel Engines with a Reformed EGR System Using an Artificial Neural Network
}

\author{
Jiwon Park ${ }^{1}$, Jungkeun Cho ${ }^{2}$, Heewon Choi ${ }^{3}$ and Jungsoo Park ${ }^{4, *}$ \\ 1 Hyundai Motor Company, 150 Hyundaiyeonguso-ro, Namyang-eup, \\ Hwaseong-si 18280, Gyeonggi-do, Korea; G.one@hyundai.com \\ 2 Hyundai Heavy Industries, 1000 Bangeojunsunhwan-doro, Dong-gu, Ulsan 44032, Korea; jkcho@hhi.co.kr \\ 3 Department of Mechanical Engineering, Graduate School, Chosun University, 309 Pilmun-daero, Dong-gu, \\ Gwangju 61452, Korea; hwchoi0924@gmail.com \\ 4 Department of Mechanical Engineering, Chosun University, 309 Pilmun-daero, Dong-gu, Gwangju 61452, Korea \\ * Correspondence: j.park@chosun.ac.kr; Tel.: +82-62-230-7057
}

Received: 17 October 2020; Accepted: 9 November 2020; Published: 11 November 2020

check for updates

\begin{abstract}
Facing the reinforced emission regulations and moving toward a clean powertrain, hydrogen has become one of the alternative fuels for the internal combustion engine. In this study, the prediction methodology of hydrogen yield by on-board fuel reforming under a diesel engine is introduced. An engine dynamometer test was performed, resulting in reduced particulate matter (PM) and NOx emission with an on-board reformer. Based on test results, the reformed gas production rate from the on-board reformer was trained and predicted using an artificial neural network with a backpropagation process at various operating conditions. Additional test points were used to verify predicted results, and sensitivity analysis was performed to obtain dominant parameters. As a result, the temperature at the reformer outlet and oxygen concentration is the most dominant parameters to predict reformed gas owing to auto-thermal reforming driven by partial oxidation reforming process, dominantly.
\end{abstract}

Keywords: diesel engine; hydrogen; NOx reduction; reforming; artificial neural network

\section{Introduction}

Recently, eco-friendly energy sources, such as electricity and fuel cells, which can replace internal combustion engines, have attracted significant attention due to extreme environmental pollution. However, eco-friendly energy sources involve several problems, such as insufficient driving range, lack of charging stations, and high vehicle prices. Researchers from MIT predicted that $60 \%$ of the world's vehicles will be powered by internal combustion engines until 2050 [1]. Therefore, research on internal combustion engines and renewable energy is continuously performed. Specifically, diesel engines, among internal combustion engines, are effective in reducing $\mathrm{CO}_{2}$ [2]. They offer many advantages, such as high efficiency and torque. However, they also emit harmful exhaust gases, such as NOx and particulate matter (PM) [3]. NOx causes acid rain, and it is converted into nitrate when it comes in contact with moisture in air. This can cause respiratory diseases $[4,5]$ in humans. Additionally, NOx is a precursor of fine dust, and thus, it reacts in air and forms extremely small particles. Diesel engines also emit significant amounts of PM [4]. To date, considerable research has been conducted to mitigate these emissions. Specifically, devices such as diesel particulate filters (DPFs) can be used for removing particulate matter. Furthermore, DPFs can be used for collecting most types of PM [6]. DPFs collect and burn the particles through post-injection. Exhaust gas recirculation (EGR) is a method in which a part of the exhaust gas is sent back to the intake air to return high-specific-heat 
gas, such as $\mathrm{CO}_{2}$ and $\mathrm{H}_{2} \mathrm{O}$, into the combustion cylinder. $\mathrm{NOx}$ is produced at high temperatures based on the Zeldovich mechanism; thereby, through cooling of the combustion chamber, EGR can mitigate the production of NOx $[7,8]$. However, this leads to unstable combustion, which increases the amount of PM. Selective catalytic reduction (SCR) is another method for reducing NOx emissions. In an SCR device, NOx is captured and reacted with ammonia. This reduces NOx emissions by $80-90 \%$ [9]. However, strengthening regulations will continue to the achievement of a sustainable vehicle [10]. Despite these combustion and post-treatment technologies, new technologies must be developed to satisfy the progressively stricter environmental regulations [5]. To date, studies have been performed on the use of various types of fuels in diesel engines [11]. The addition of hydrogen to a diesel engine can simultaneously decrease NOx and PM emissions $[12,13]$. Cho et al. examined the effect of hydrogen addition to a diesel engine. They observed that NOx and PM emissions can be decreased simultaneously via hydrogen addition [14]. Shin et al. studied the chemical reaction involved in hydrogen addition to a diesel engine. They observed that hydrogen rapidly consumes $\mathrm{OH}$ radicals, faster than diesel fuel does, thereby producing longer ignition delays. Therefore, hydrogen addition lowers the maximum pressure and maximum temperature, which decreases NOx emissions [15]. Tsolakis et al. studied the addition of reformed gas to a diesel engine. They used a low pressure (LP)-EGR and a reformer to generate hydrogen without a hydrogen tank. They observed that NOx emission decreased when the EGR rate was increased. Additionally, owing to the hydrogen contained in the EGR gas, the premixed ratio was increased, and PM emission was reduced simultaneously [16]. Sher and Sher introduced the internal production of hydrogen under the internal combustion engine. They proposed the theoretical possibility in hydrogen production using steam reforming during the thermodynamic cycle [17]. Chen et al. investigated catalytic fuel reforming under diesel engine. The hydrogen and CO yield was well simulated, considering detailed elementary reactions under different reaction temperatures [18]. Although many possibilities of reforming technologies in an engine system have been introduced, the most important thing is the applicability to a real system having stable reforming performance under various operating conditions. From that point of view, numerical approaches can give many ideas covering a wide range of engine operating conditions. Recently, prediction methodologies using neural networks have also been used for the internal combustion engine. Jeon et al. proposed a model for predicting the performance and fuel consumption of marine engines using artificial neural networks (ANNs). They compared the ANN with a previously developed linear regression model and reported that the ANN exhibited a higher prediction rate [19]. Li et al. constructed a model to predict the NOx and smoke emissions of diesel engines. They utilized a multilayer perceptron (MLP) neural network model, which achieved extremely high prediction rates for NOx and smoke emissions [20]. De Cesare et al. determined whether a NOx sensor can be replaced with a virtual sensor. The results were compared in the NEDC (New European driving cycle) mode, and the accuracy of the virtual sensor was determined to be extremely high [21].

In this study, a reformed gas application on a diesel engine was experimentally and numerically performed. It was apparent that reformed hydrogen with an EGR system could be proposed for the simultaneous reduction in NOx and PM emitted from a small diesel engine. Based on test results with on-board reforming, the present study focused on the data training and sensitivity analysis applying an artificial neural network. Dominant parameters are suggested to predict reforming yield under the on-board fuel reforming system in a diesel engine.

\section{Methodology}

\subsection{Experimental Setup}

A schematic diagram of the experimental setup with all the equipment is shown in Figure 1. Detailed descriptions of the main experimental equipment are also provided in the figure. The target engine was a four-cylinder in-line engine with common rail direct injection (CRDI). Experiments were conducted on all parameters, except EGR and injection timing, with mapping. The HP EGR (High 
pressure exhaust gas recirculation) valve was set to be inoperative, and the EGR rate was adjusted solely via the LP EGR valve and backpressure valve. The injection timing was adjusted such that the combustion rate was 50\% between after top dead center (ATDC) 8 and 9 to set the combustion efficiency standard. The specifications of the engine are listed in Table 1.

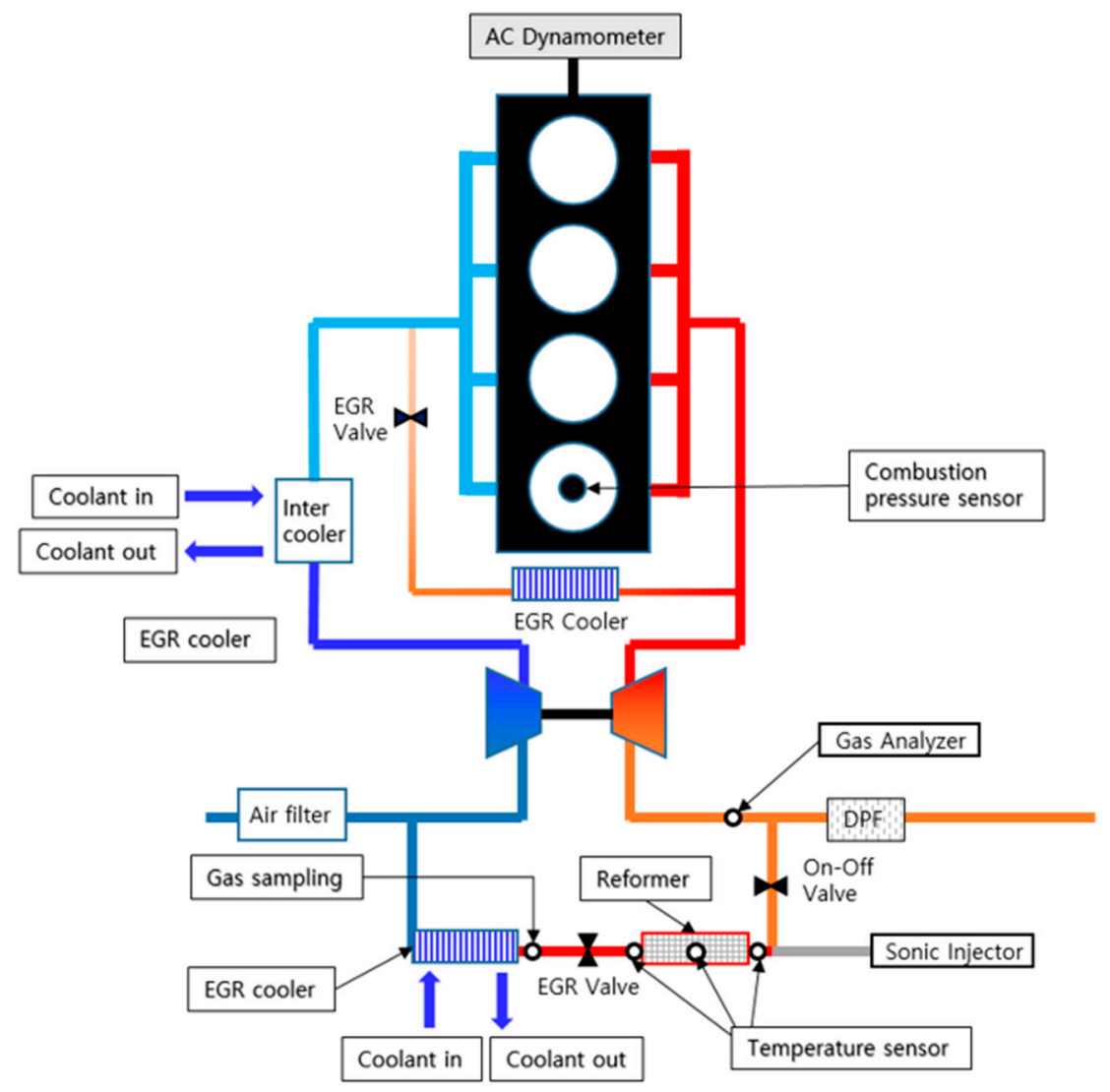

Figure 1. Schematic diagram of the experimental setup.

Table 1. Engine specifications.

\begin{tabular}{cc}
\hline Parameter & Specifications \\
\hline Engine type & In-line 4 cylinder \\
Bore $(\mathrm{mm})$ & 77.2 \\
Stroke $(\mathrm{mm})$ & 84.5 \\
Compression ratio & 17.3 \\
Rated output power $(\mathrm{kW})$ & 100 \\
Injection type & Common rail direct injection \\
Emission regulation & Euro-6 \\
\hline
\end{tabular}

The sample injected from the sample inlet of the gas chromatograph was vaporized via heating and sent to the column filled with the carrier gas together with the gas phase in the liquid phase. The carrier gas moved to the outlet and came in contact with the filler while passing through the column and repeating the adsorption and distribution. At this time, a difference existed between the speeds at which each component in the sample moved through the column due to the difference in the partition coefficient from the moving phase to the fixed phase. Each component that was separated based on the speed of movement was detected by the detector, and a chromatogram based on the elution order was obtained. The calibration gas (consisting of $5 \%$ hydrogen, $5 \% \mathrm{CO}$, and $90 \%$ argon) was measured, as shown in Figure 2. 


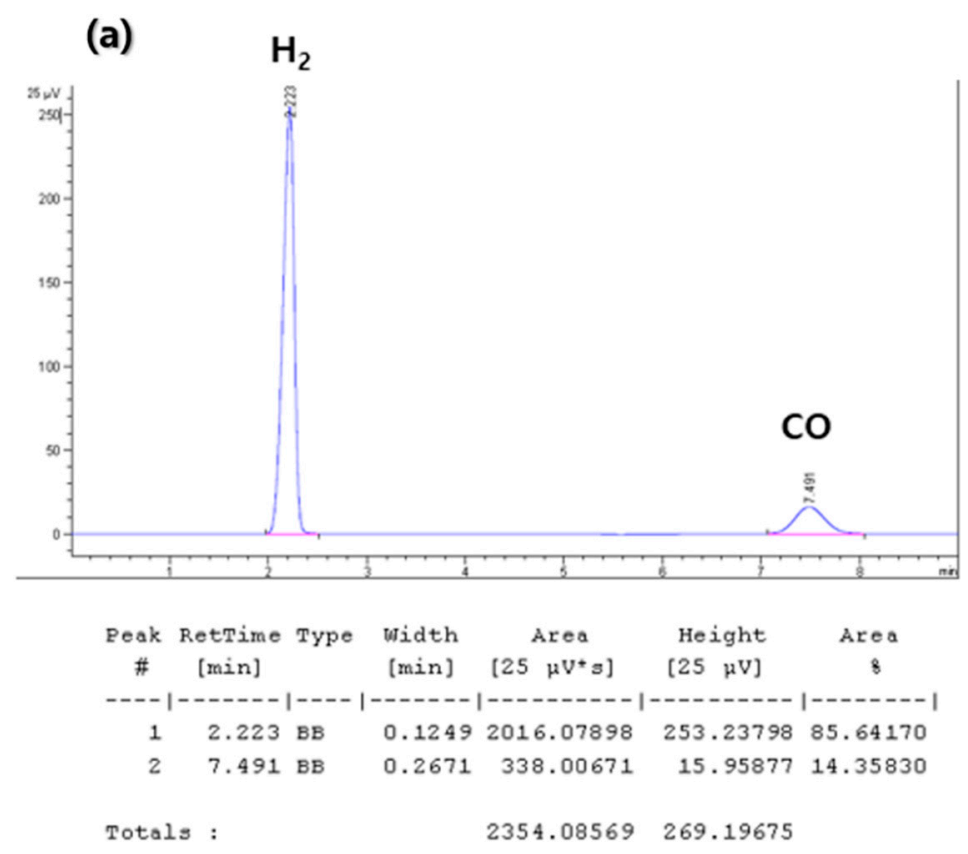

(b)

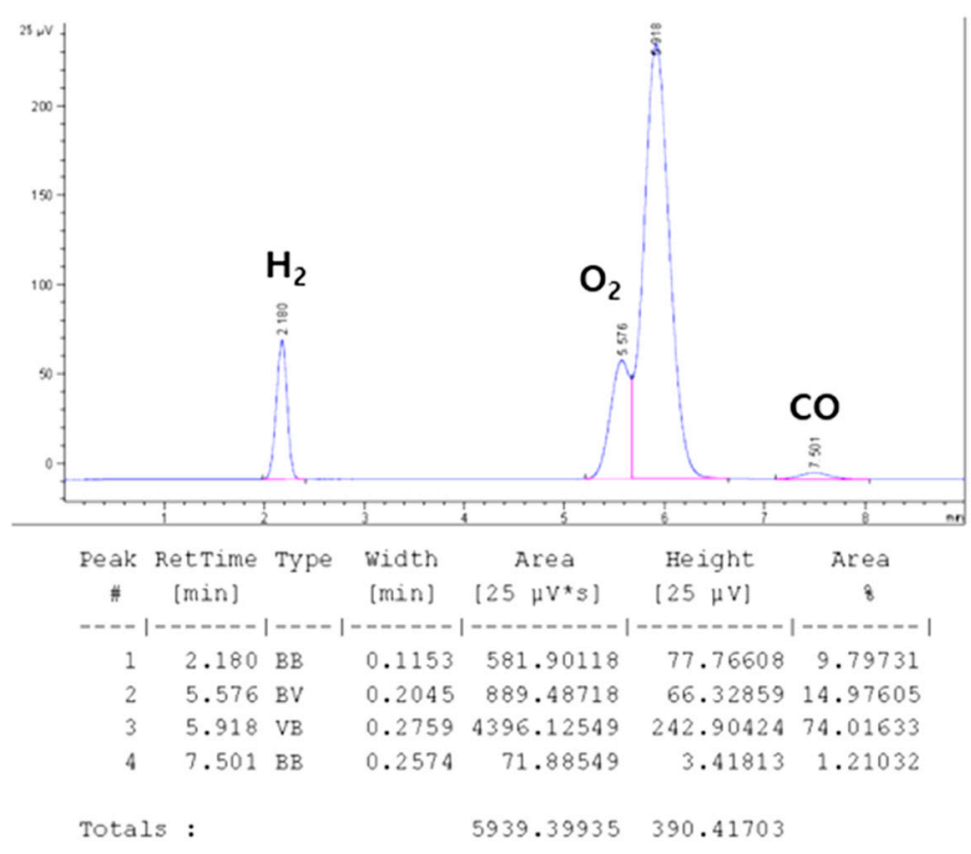

Figure 2. (a) Measured sample of $5 \% \mathrm{H}_{2}$ and $5 \% \mathrm{CO}$ calibration gas; (b) Measured sample of reformed gas. (x-axis: time, $\mathrm{y}$-axis: $\mu \mathrm{V}$ ).

Figure 2a shows the area under the 5\% hydrogen and 5\% carbon monoxide peaks. The $\mathrm{X}$-axis represents time, and the $y$-axis represents $\mu \mathrm{V}$. The reformed gas obtained from downstream of the reforming device was measured, and the area under the peaks of the reformed gas was obtained, as shown in Figure 2b. Hence, it is possible to calculate the volume ratio of hydrogen and carbon monoxide contained in the exhaust gas.

A MEXA-9100DEGR gas analyzer (Horiba, Kyoto, Japan) was used. The analyzer can measure the concentrations of $\mathrm{CO}, \mathrm{CO}_{2}$, total hydrocarbon (THC), $\mathrm{O}_{2}$, and $\mathrm{NOx}$. Additionally, the EGR rate was calculated using the $\mathrm{ECO}_{2}$ value, which corresponds to the $\mathrm{CO}_{2}$ concentration in the intake air. 
The detailed specifications of the gas analyzer are listed in Table 2. The total hydrocarbon (THC) concentration was measured using the number of $C$. Because we used $\mathrm{C}_{3} \mathrm{H}_{8}$ gas, we set the span value by multiplying the value of the calibration gas by 3 .

Table 2. Specifications of the gas analyzer.

\begin{tabular}{|c|c|c|c|c|}
\hline Model & \multicolumn{4}{|c|}{ MEXA-9100DEGR (Horiba) } \\
\hline \multirow{4}{*}{ MEXA 9100DEGR } & Emission & Method & Range & Span \\
\hline & $\begin{array}{c}\text { THC } \\
\text { (Total hydrocarbon) }\end{array}$ & $\begin{array}{c}\text { FID } \\
\text { (Flame ionization detector) }\end{array}$ & 20000 ppm & $\begin{array}{c}\mathrm{C}_{3} \mathrm{H}_{8} \\
13503 \mathrm{ppm}\end{array}$ \\
\hline & $\begin{array}{l}\mathrm{CO} \\
\mathrm{CO}_{2}\end{array}$ & $\begin{array}{c}\text { NDIR } \\
\text { (Non-dispersive infrared) }\end{array}$ & 3000 ppm & $\begin{array}{c}\mathrm{CO} \\
2702 \mathrm{ppm} \\
\mathrm{CO}_{2} / \mathrm{N}_{2} \\
14.54 \%\end{array}$ \\
\hline & $\begin{array}{c}\text { NOx } \\
\text { (Nitric oxides) }\end{array}$ & $\begin{array}{c}\text { CLD } \\
\text { (Chemiluminescence } \\
\text { detector) }\end{array}$ & 5000 ppm & $\begin{array}{c}\mathrm{NO} / \mathrm{N}_{2} \\
3980 \mathrm{ppm}\end{array}$ \\
\hline
\end{tabular}

The reforming performance improves when the fuel is atomized and uniformly distributed in the catalyst [22]. Therefore, the fuel in this study was atomized using an ultrasonic injector. An ultrasonic injector, S 40 (CERATORQ, Seoul, Korea), was used, and a controller was used to control the flow rate based on the ambient temperature and pressure conditions, as shown in Figure 3.
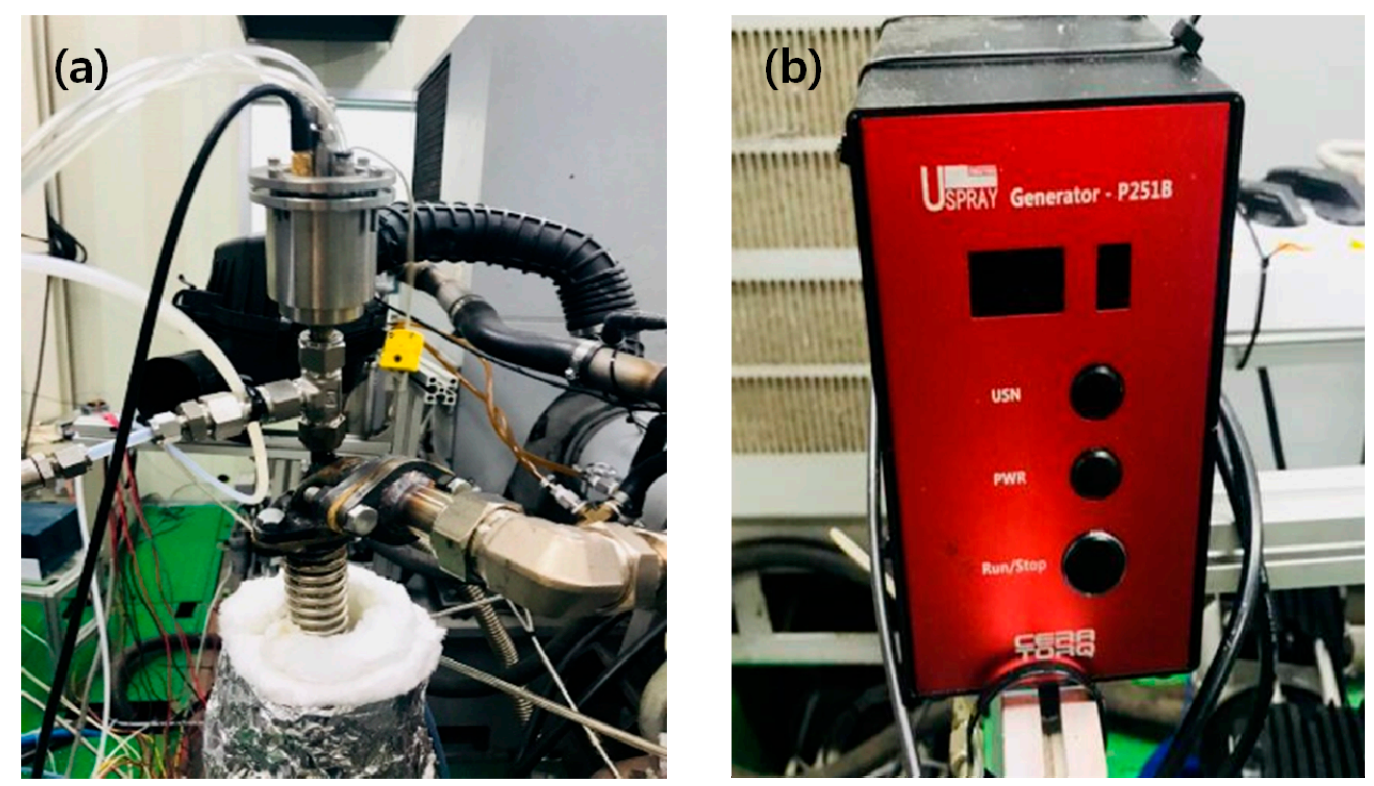

Figure 3. (a) Ultra sonic injector; (b) Injector controller.

The in-cylinder pressure was measured using a Kistler's 6065A41(KISTLER Korea, Gyeonggi-do, Korea) product as opposed to the injector in the cylinder. The product is a glow plug type and can measure in-cylinder pressure in real-time. It can measure pressures in the range of 0-250 bar and has a sensitivity of approximately $20 \mathrm{pC} / \mathrm{bar}$ at $350{ }^{\circ} \mathrm{C}$. The combustion pressure in the cylinder was monitored using a product termed Kibox (manufactured by KISTLER Korea, Gyeonggi-do, Korea), and the ignition timing was determined via combustion analysis. The engine specifications were input for precise measurement. The data were collected over 100 cycles, and the average pressure value was used.

A high-performance monolith catalyst with a high durability of 30\% (5\% Platinum (Pt)-Gadolinia doped Ceria (GDC) $+70 \%$ C11PR (commercial pre-reforming catalyst)) was used as the reformer. 
The hydrogen conversion efficiency of the catalyst was approximately $50 \%$, and its durability was confirmed to be excellent based on a $100 \mathrm{~h}$ durability test performed after mounting the reformer on the diesel engine. The catalyst housing was designed and manufactured, as shown in Figure 4. A cartridge heater was used to heat the gas and fuel before they would reach the catalyst. In the lower part with the catalyst, a $4 \mathrm{~kW}$ ceramic band heater with ceramic insulation was used. The catalyst reacted via steam reforming, partial oxidation reforming, water shift reforming, and auto-thermal reforming. Thus, the reforming was performed through a highly complicated process, although the reforming efficiency was high. Well-known hydrocarbon fuel reforming reactions over Pt catalysts can be found in [23] referred to as auto-thermal reforming, which is combined reforming between steam reforming and partial oxidation.

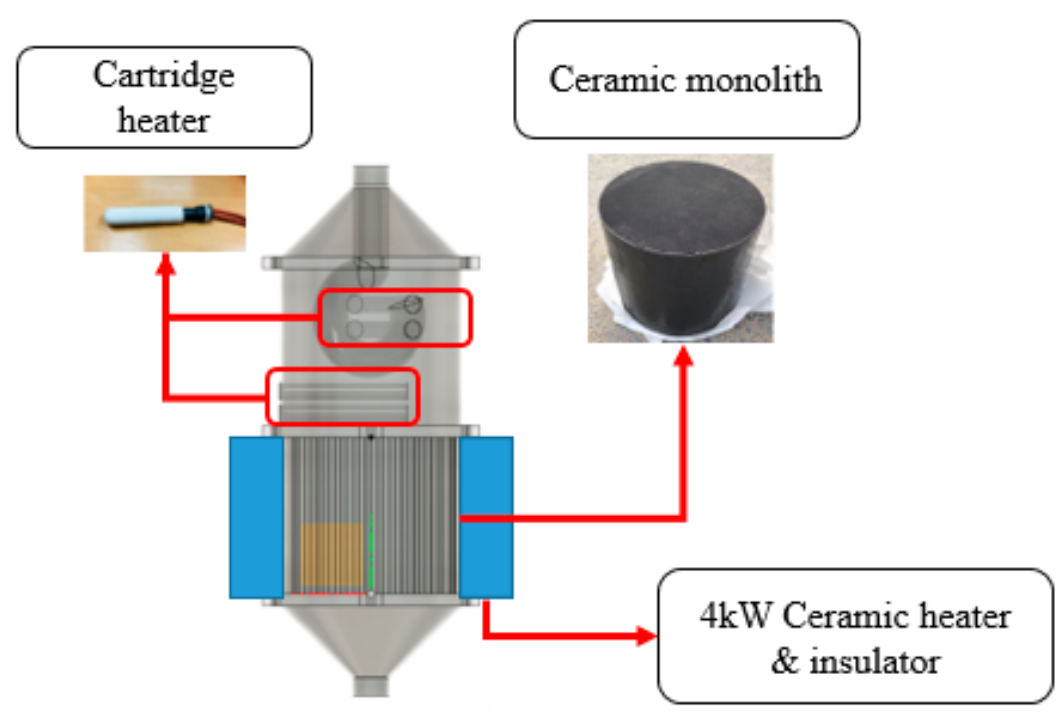

Figure 4. Catalyst housing in the reformer.

A $4 \mathrm{~kW}$ ceramic heater and four $500 \mathrm{~W}$ cartridge heaters were used to maintain the catalyst activation temperature of the reformer. The ceramic heater was controlled on/off to maintain the temperature, and a proportional-integral-derivative (PID) controller was used in the cartridge heater for precise temperature control. Specifically, a ceramic case was prepared and wrapped around the cartridge heater to prevent oxidation of the fuel. This ensured that the fuel did not come into contact with the cartridge heaters before reaching the catalyst. Additionally, the cartridge heater was controlled using a PID controller. In a further study, an additional heater used in this study, which can decrease system efficiency, can be substituted for a waste heat recovery strategy using hot temperature from the EGR cooler.

\subsection{Experimental Procedure}

Experiments were performed in two ways.

The operating conditions of the engine are listed in Table 3.

Table 3. Operating conditions for artificial neural network (ANN) model training and verification.

\begin{tabular}{cccccccccc}
\hline \multicolumn{1}{c}{ For ANN Model Training } \\
\hline $\begin{array}{c}\text { Engine } \\
\begin{array}{c}\text { Speed } \\
(\mathrm{rpm})\end{array}\end{array}$ & $\begin{array}{c}\text { BMEP } \\
(\mathrm{bar})\end{array}$ & $\begin{array}{c}\text { EGR } \\
(\%)\end{array}$ & $\begin{array}{c}50 \% \text { burn } \\
(\text { CA ATDC })\end{array}$ & $\begin{array}{c}\text { Reforming } \\
\text { fuel } \\
(\mathrm{g} / \mathrm{h})\end{array}$ & $\begin{array}{c}\text { Engine } \\
\text { Speed } \\
(\mathrm{rpm})\end{array}$ & $\begin{array}{c}\text { BMEP } \\
(\mathrm{bar})\end{array}$ & $\begin{array}{c}\text { EGR } \\
(\%)\end{array}$ & $\begin{array}{c}50 \% \text { burn } \\
(\text { CA ATDC })\end{array}$ & $\begin{array}{c}\text { Reforming } \\
\text { fuel } \\
(\mathrm{g} / \mathrm{h})\end{array}$ \\
\hline 1500 & 6,8 & 10 & $8-9$ & 330 & 1500 & 8,9 & 10 & $8-9$ & 330 \\
1750 & 8,10 & 10 & $8-9$ & 330 & 2200 & 8 & 10 & $8-9$ & 330 \\
2000 & 10,12 & 10 & $8-9$ & 330 & 2400 & 10 & 10 & $8-9$ & 330 \\
\hline
\end{tabular}


Experiments for training the ANN model were performed for six brakes mean effective pressure (BMEP) values, while experiments for verification of the ANN model were performed for four BMEP values, as shown in Table 3. In Figure 5, the box region corresponds to the desired region where the reforming catalyst can be used, as suggested by the OEM (Original equipment manufacturer). Oxygen is required for the partial oxidation reforming reaction; thus, the amount of catalyst that could be used in the high-load region was limited. Furthermore, the temperature was low in an exceedingly-low-load region, and thus, the activation temperature of the catalyst was also limited to a certain value. The hatched area corresponds to the experimental area that was used to train the ANN model, while the red dot denotes the point at which additional experiments were performed under other operating conditions that were not used for training. The yellow dot denotes the point used for the ANN model training and verification.
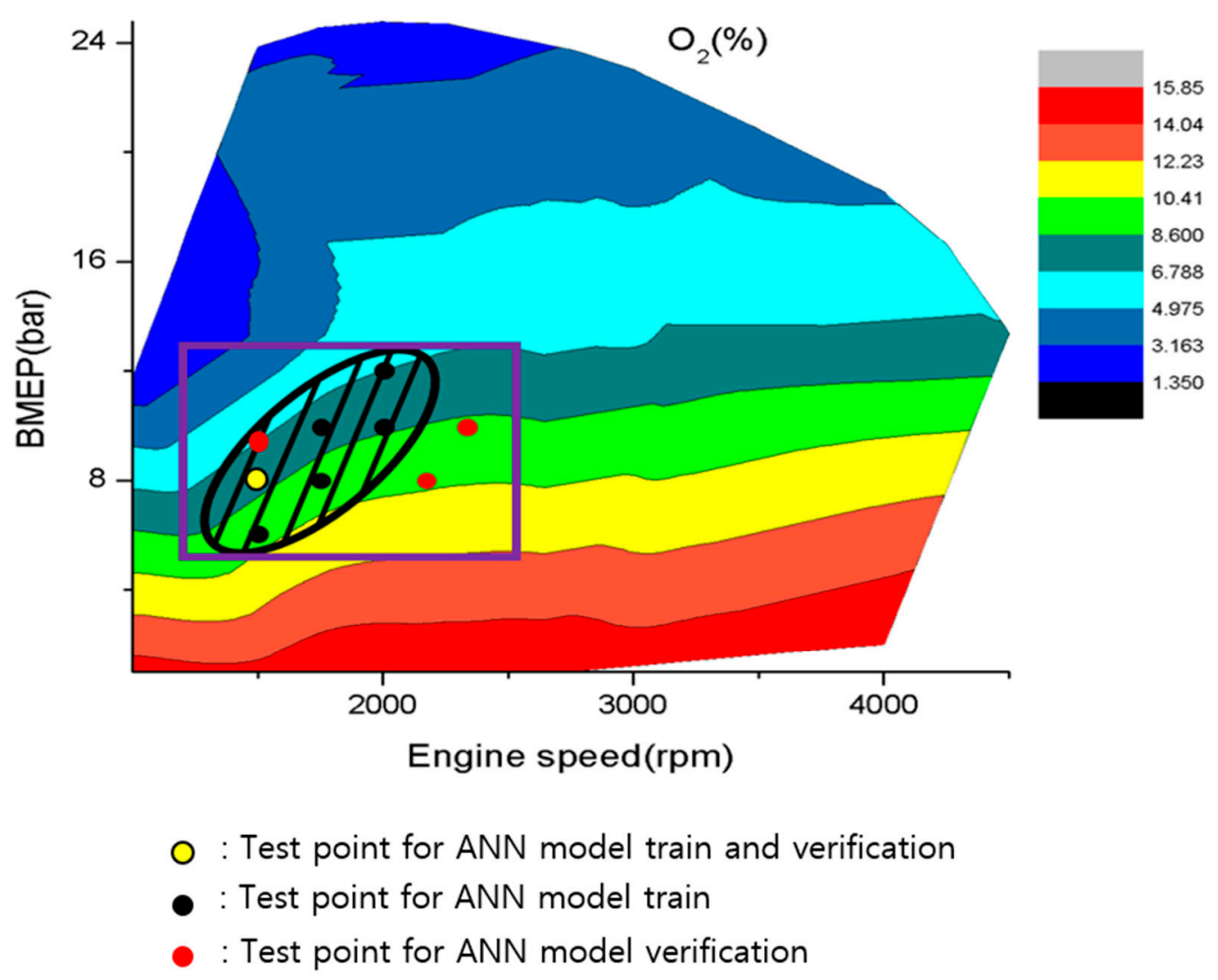

Figure 5. Operating conditions on RPM-load map.

The engine was controlled through a map of the ECU (Engine control unit or electronic control unit), and only the LP-EGR was controlled using a separate backpressure valve and an EGR valve. The experiment was performed with an EGR rate of $10 \%$. First, the engine test was performed without heating the catalyst. Experimental data were obtained for each of the six BMEP values, and experiments were performed using the reformer to compare the results. The temperature of the reforming catalyst was controlled to between $500{ }^{\circ} \mathrm{C}$ and $600{ }^{\circ} \mathrm{C}$ via the waste heat of the exhaust gas and heater. Furthermore, the amount of fuel injected into the combustion chamber was adjusted to maintain the output because the output increased due to the addition of the reforming gas. The EGR rate and supplied-hydrogen ratio were calculated using the following equations:

$$
\text { EGR rate }(\%)=\frac{\left.\mathrm{CO}_{2} \text { (intake port }\right)}{\left.\mathrm{CO}_{2} \text { (exhaust port }\right)} \times 100
$$




$$
\text { Supplied hydrogen by energy ratio }(\%)=\frac{m_{H_{2}} Q_{L H V, H_{2}}}{m_{H_{2}} Q_{L H V, H_{2}}+m_{\text {diesel }} Q_{L H V, \text { diesel }}} \times 100
$$

The EGR rate was calculated via Equation (1) using the ratio of the total $\mathrm{CO}_{2}$ concentration and $\mathrm{CO}_{2}$ concentration in the intake. The concentration of hydrogen was calculated as the ratio of the lower heating value of hydrogen (LHV) of the injected total fuel to the LHV value of the injected hydrogen. The concentration of injected hydrogen was calculated using Equation (2).

Additionally, the reforming gas contains $\mathrm{CO}_{2}$, and thus, the $\mathrm{ECO}_{2}$ value slightly increases when the reaction starts. However, this also occurs because of the reforming gas; hence, the experiment was performed without adjusting the valve.

\subsection{Artificial Neural Network}

Neural networks can have structures with various shapes. However, the MLP is the most widely used type of neural network model for data analysis [20]. An MLP neural network model consists of an input layer, a hidden layer, and an output layer. Figure 6 shows the structure of a neural network and the training process used in this study.

(a)

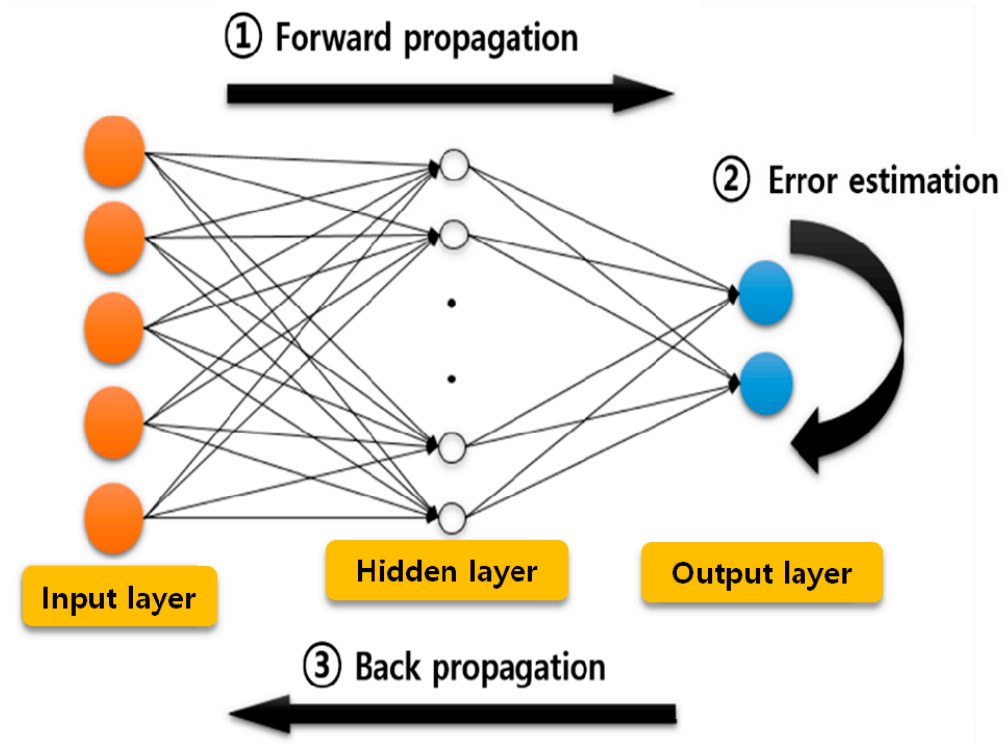

(b)

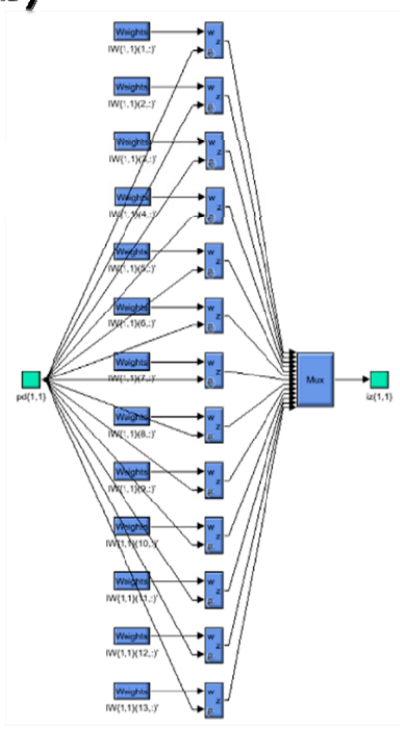

Figure 6. (a) Training process used for artificial neural network (ANN) model; (b) ANN model in MATLAB $^{\circledR}$.

In this study, a backpropagation neural network was trained as follows:

- Step 1: The input value was applied to the input node in the neural network, and multiplication or addition with the weight was repeated several times to calculate the output value based on the input.

- Step 2: The output value differed from the target output value; thus, the error between the predicted output and target output was calculated in the learning process in the neural network.

- Step 3: The weights were reduced or increased to reduce the error.

- $\quad$ Step 4: The extent to which each weight should be changed was determined.

- Step 5: The weight was updated to the value determined in Step 4. The processing of the neural network proceeded from the input layer to the hidden layer and then to the output layer. However, the weight update proceeded from the output layer to the hidden layer and then to the input layer. Hence, this process is termed backpropagation. 
- Step 6: Steps 1-5 were repeated until the error decreased to an appropriate level for all the learning data.

The learning model was constructed using MATLAB ${ }^{\circledR}$ (V 2017, Natick, MA, USA)'s Neural Net fitting application. The parameters affecting the catalyst were selected as the input variables for the learning ANN model. Temperature significantly affects the activation of the catalyst. Therefore, the temperature of the front, middle, and rear ends of the catalyst housing were selected as the variables. Additionally, the amount of oxygen discharged from the engine was selected as a variable because the oxygen content significantly affects partial oxidation reforming. Specifically, THC, CO, and NOx emissions decreased when the reformed gas containing hydrogen was supplied to the cylinders. Moreover, the catalyst was significantly affected by the gas hourly space velocity (GHSV) value [24,25]. Therefore, the engine speed, load, and EGR rate (which are directly related to GHSV) constituted the variables. Hydrogen and $\mathrm{CO}$ were used as output variables and had the greatest influence on combustion among the components of the reformed gas. Hence, 11 parameters were selected as input variables for learning based on the test data from the operating conditions listed in Table 3.

Based on the measured data and the aforementioned input parameters, the ANN model was trained using $70 \%$ of the measured data as training data, $15 \%$ as test data (which was not used to train the $\mathrm{ANN}$ ), and $15 \%$ as validation data to compensate for the error in the backpropagation process.

The accuracy and quality of the ANN model were assessed in terms of the root mean square error (RMSE), $\mathrm{R}^{2}$ coefficient, and mean absolute prediction error (MAPE). RMSE denotes the average difference between predicted and experimental data. $R^{2}$ indicates the extent to which the regression line represents the actual dataset; it can vary from 0 to 1 . In this study, $R^{2}$ was close to 1 , and thus, it represents a perfect ANN prediction model. MAPE indicates the prediction error of the ANN model. The three parameters can be determined using the following equations [26]:

$$
\begin{gathered}
\text { RMSE }=\sqrt{\frac{1}{N} \sum_{i=1}^{N}\left(y_{i}-y_{k}\right)^{2},} \\
R^{2}=1-\frac{\sum_{i=1}^{N}\left(y_{i}-y_{k}\right)^{2}}{\sum_{i=1}^{N}\left(y_{i}-\widetilde{y}\right)^{2}} \\
\text { MAPE }=\frac{1}{N} \sum_{i=1}^{N}\left|\frac{y_{i}-y_{k}}{y_{i}}\right| .
\end{gathered}
$$

The trained model was verified under the different operating conditions listed in Table 3. Simulink ${ }^{\circledR}$ was used to construct the calculation control logic. If 11 input data were entered from signal 1 to signal 11 (engine speed, load, temperature, EGR rate, etc.), the neural network model predicted the values of hydrogen and carbon monoxide as the output values.

\section{Results and Discussion}

\subsection{Effect of Reformed Gas Addition}

Figure 7 shows the experimental results for cylinder pressure against the crank angle without and with reformed gas addition under $1500 \mathrm{rpm}$, for a BMEP of 6 bar. The hydrogen content was $0.5-1.2 \%$ by energy. It was confirmed that the ignition was delayed, and the maximum pressure decreased when the reformed gas was injected. 


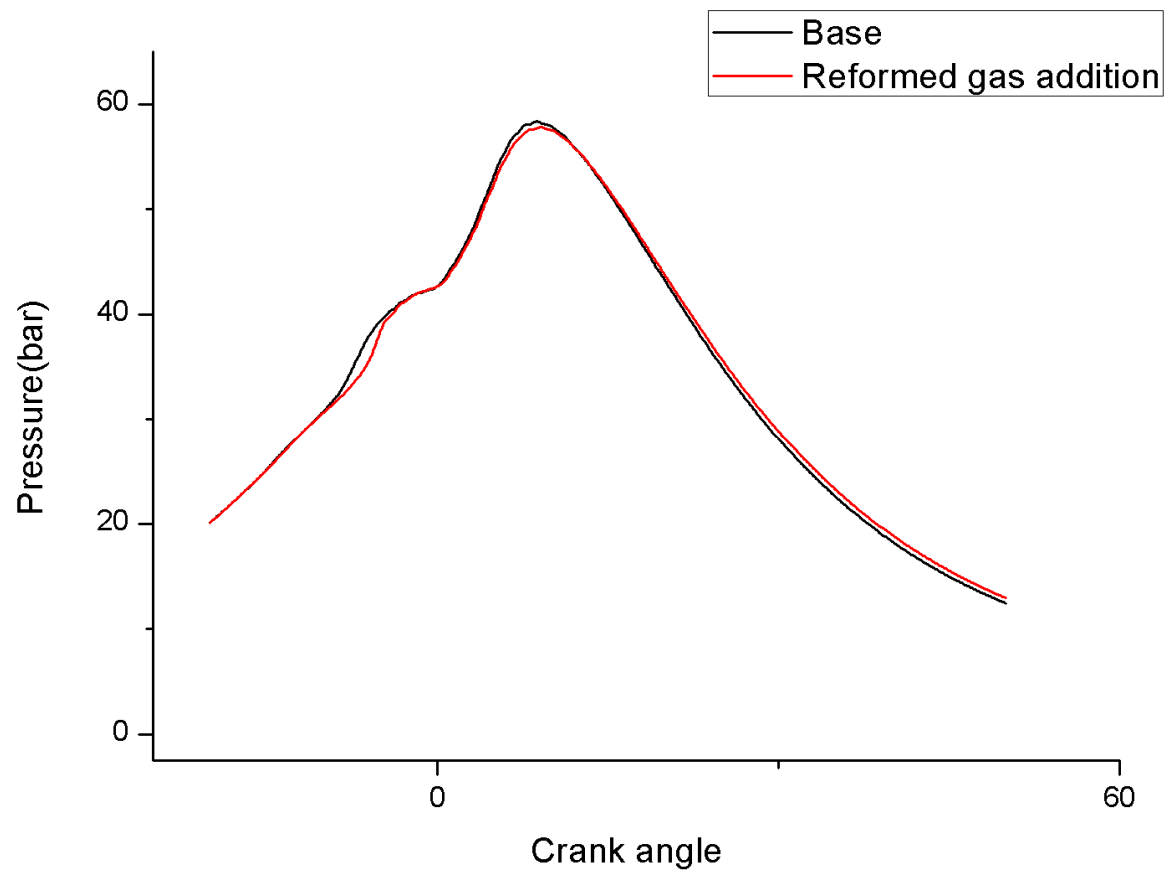

Figure 7. Cylinder pressure against crank angle under $1500 \mathrm{rpm}$ for a six brakes mean effective pressure (BMEP) of 6 bar.

Figures 8-10 show the effect of reformed gas addition on NOx and PM emissions. The addition of the reformed gas led to a further reduction in NOx when compared with $\mathrm{H}_{2}$ addition alone. The results indicated that $\mathrm{CO}_{2}, \mathrm{CO}$, and other gases with high heat capacity were generated and that the temperature of the cylinder decreased. The experimental results for NOx emission are shown in Figure 8.

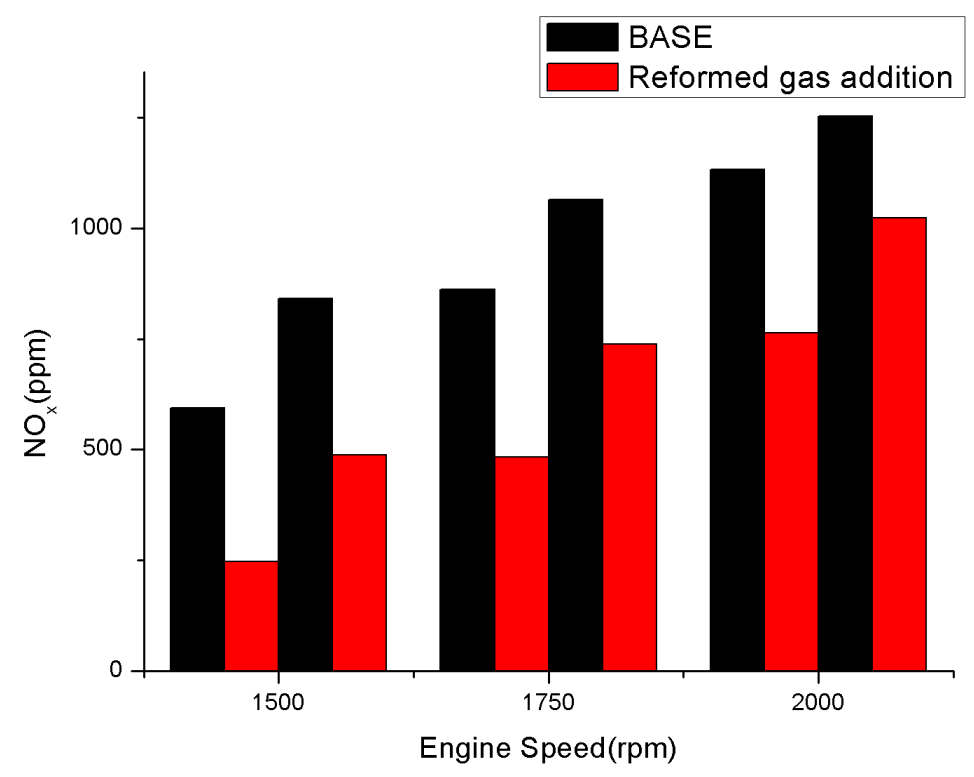

Figure 8. NOx emissions with only diesel (base) and with reformed gas addition. 


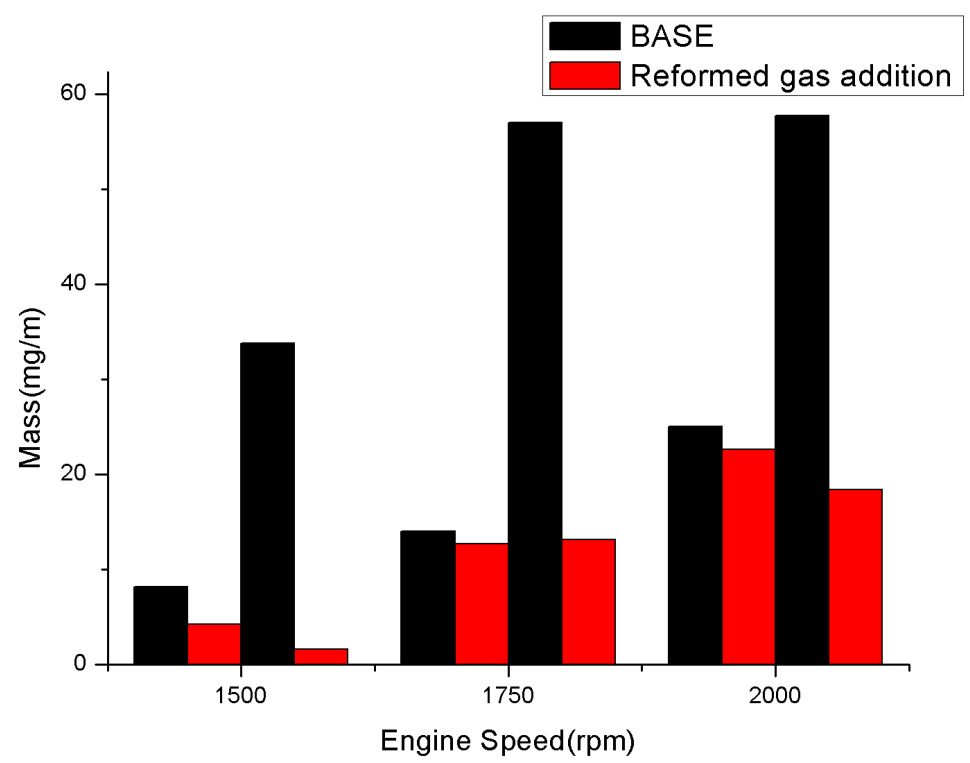

Figure 9. Particulate mass with only diesel (base) and with reformed gas addition.

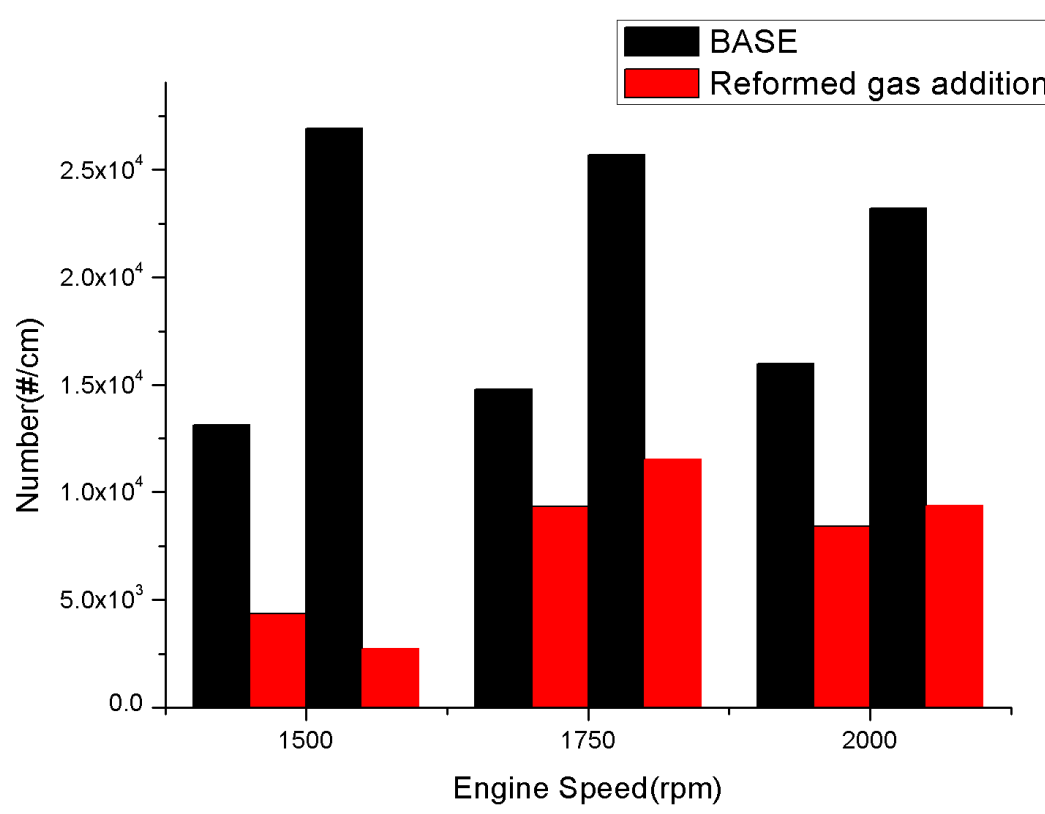

Figure 10. Number of particulates with only diesel only (base) and with reformed gas addition.

PM emission also decreased significantly. The number, as well as mass of the smaller particulates, decreased. The size of the larger particulates decreased when the oxidation was accelerated, and the smaller particulates quickly disappeared. Specifically, the PM emission decreased at high loads, and this was considered to promote PM oxidation because the temperature of the cylinder under high loads was higher than that under low loads. The PM emission results are shown in Figures 9 and 10.

\subsection{ANN Training Results}

A greater number of neurons in the learning model increases the probability of over-fitting, which consequently reduces data prediction accuracy because the training model focuses only on training data. To prevent over-fitting, we constructed a learning model after comparing the number of neurons from 1 to 15. A Bayesian algorithm was used because the number of data points was low. The Bayesian algorithm is used when the number of data points is low. The most accurate prediction was obtained when the number of neurons was 13. Therefore, the number of neurons for the learning model used 
in this study was set as 13 . Figure 11 shows the regression results with 13 neurons with respect to training data, test data, and integrated data between training and test data. As shown in the figure, suitable regression values were obtained with 13 neurons.
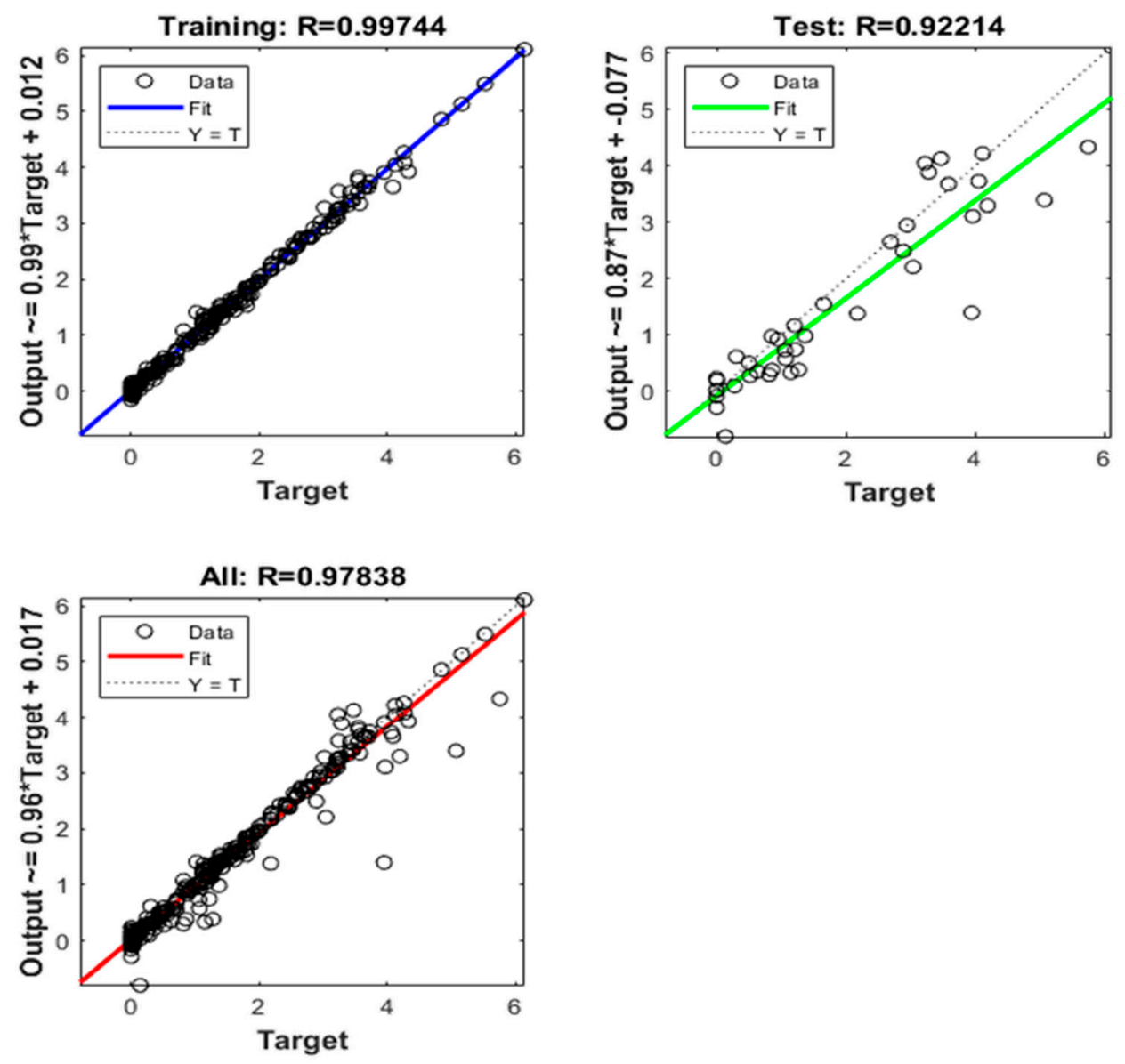

Figure 11. Regression plot with 13 neurons.

The actual measured amounts of $\mathrm{H}_{2}$ and $\mathrm{CO}$ in the reformed gas and the amounts predicted using the neural network model are shown in Figure 12. The sample number on the x-axis represents the number of tests based on the operating conditions listed in Table 3. 

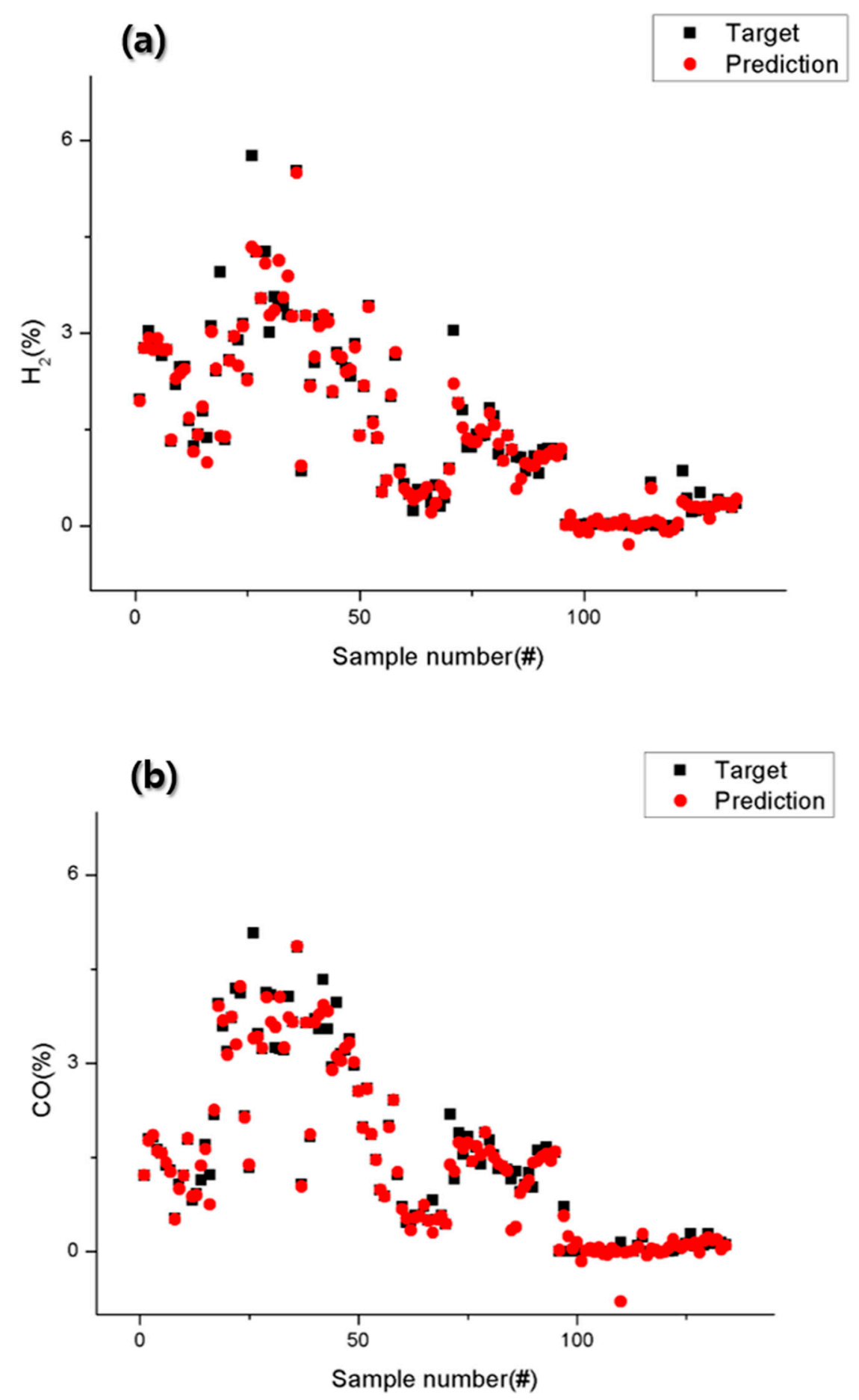

Figure 12. Target (measured) and predicted values of (a) $\mathrm{H}_{2}$ and (b) CO content.

\subsection{Model Verification and Sensitivity Analysis}

Figure 13 shows a comparison between the predicted and target values for the ANN model verification under the operating conditions listed in Table 3. As shown in the figure, the $\mathrm{H}_{2}$ reforming tendencies were well-matched at $1500 \mathrm{rpm}$, which is within the operating range used for training; however, the tendencies were underestimated below 2200 and $2400 \mathrm{rpm}$, which was beyond the operating range used in training. In contrast, the $\mathrm{CO}$ reforming tendencies were well-matched under every operating condition. However, the values were underestimated below 2200 and $2400 \mathrm{rpm}$, which was beyond the operating range used in training. This indicates that ANN training with 
extremely few operating conditions (six in this study) leads to a reduction in prediction accuracy despite the optimization of the number of neurons. Furthermore, it is necessary to consider more factors that affect the reforming reaction under high-rpm and high-load operating conditions.
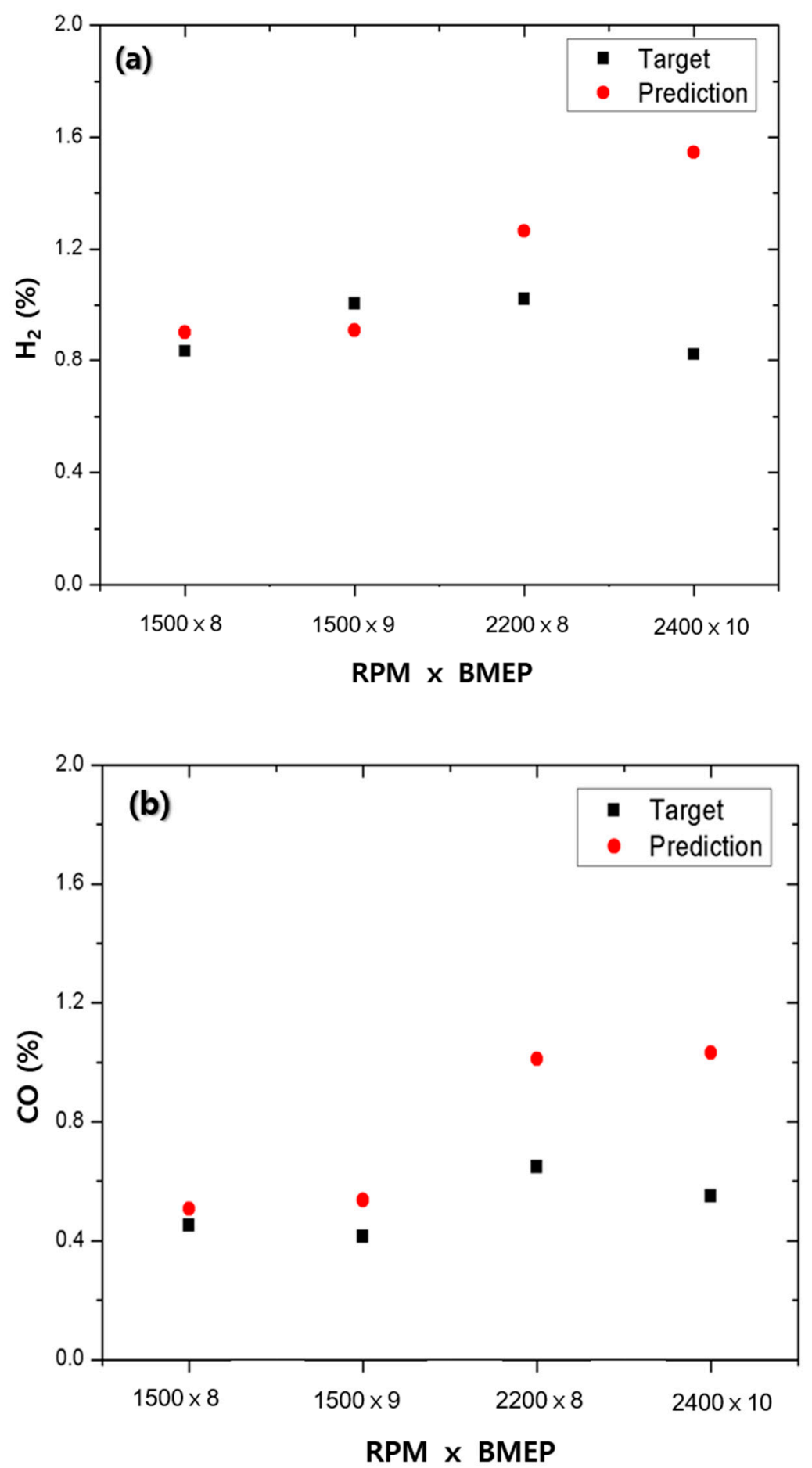

Figure 13. Predicted and target (measured) values of (a) $\mathrm{H}_{2}$ and (b) $\mathrm{CO}$ content for ANN model verification.

A sensitivity analysis was performed to determine the most sensitive of the selected 11 variables. The sensitivity of each parameter was compared to determine the variables that affect the catalyst performance most significantly. The variables were excepted one by one during the training process, 
and the training results were compared with the test data. How far the trained data was from the test data can be deduced as the R-value shown in Table 4.

Table 4. $R$ values and ranks as per sensitivity analysis for each input variable.

\begin{tabular}{cccccc}
\hline & Training & Test & All & Excepted Variable & Rank \\
\hline 1 & 0.99297 & 0.7446 & 0.94482 & Torque & 7 \\
2 & 0.99297 & 0.56793 & 0.92883 & Speed & 4 \\
3 & 0.99447 & 0.7804 & 0.96509 & T_housing_in & 9 \\
4 & 0.99467 & 0.7616 & 0.97372 & T_housing_mid & 8 \\
$\mathbf{5}$ & $\mathbf{0 . 9 9 4 2}$ & $\mathbf{0 . 4 0 0 3 1}$ & $\mathbf{0 . 8 8 2 2 5}$ & T_housing_out & $\mathbf{1}$ \\
6 & 0.99482 & 0.50265 & 0.86306 & $\mathrm{CO}_{2}$ & 3 \\
7 & 0.99096 & 0.71547 & 0.93888 & $\mathrm{ECO}_{2}$ & 6 \\
8 & 0.98921 & 0.80033 & 0.94139 & $\mathrm{THC}$ & 10 \\
$\mathbf{9}$ & $\mathbf{0 . 9 9 5 1 8}$ & $\mathbf{0 . 4 8 1 1 9}$ & $\mathbf{0 . 8 5 5 5 7}$ & $\mathrm{O}_{2}$ & $\mathbf{2}$ \\
10 & 0.99602 & 0.57432 & 0.91795 & $\mathrm{NO}_{\mathbf{X}}$ & 5 \\
11 & 0.99215 & 0.80274 & 0.91388 & $\mathrm{CO}$ & 11 \\
\hline
\end{tabular}

As shown in Table 4, the largest error between the training and test data was observed when the T_housing_out referring temperature at the downstream of the catalyst was excepted. The sensitivity ranking results indicate that $\mathrm{T}$ _housing_out and $\mathrm{O}_{2}$ are the most effective variables for improving reforming performance. After all, results from sensitivity analysis suggest that the main reforming reaction in this study is mainly driven by partial oxidation, which is reasonable.

\section{Conclusions}

In this study, a reformed gas addition method using a reforming catalyst was employed to reduce harmful emissions in the exhaust gas of a diesel engine. Experiments were performed using a 1.6-L engine and a reforming catalyst on the LP-EGR line. A neural network was used to predict the composition of the reforming gas, which changes continuously in real-time. The results are summarized as follows:

1. The addition of a reforming gas to a diesel engine can reduce NOx emissions. A longer ignition delay reduces the maximum pressure and temperature in the combustion chamber; this, in turn, mitigates the production of NOx, which occurs mainly at high temperatures following the Zeldovich mechanism. Furthermore, the addition of reforming gas increases the premixing rate because the gas enters the intake line through the LP EGR line. Therefore, the rich region decreases, and the lean region temperature rises, which promotes PM oxidation.

2. The EGR rate, catalyst temperature, exhaust gas composition, and engine operating conditions were selected as input data for the ANN learning model. The amount of hydrogen and carbon monoxide production was selected as the output data. The training model was composed of 134 datasets, and the prediction accuracy is $92.2 \%$. When the number of neurons was 13 , the model exhibited the highest prediction accuracy.

3. The ANN model exhibited a low prediction accuracy for experimental conditions that were not used for training. Therefore, a prediction model for a wider range of operating conditions can be constructed by acquiring and learning more data.

4. The sensitivities of the variables affecting the accuracy of the catalyst performance prediction model were compared. Partial oxidation reforming is an exothermic reaction, and thus, a high temperature at the rear end of the catalyst indicates effective reforming. Therefore, the temperature and amount of oxygen downstream of the catalyst affect the reforming performance most significantly.

Author Contributions: Conceptualization, J.P. (Jiwon Park) and J.C.; methodology, J.P. (Jiwon Park) and J.C.; validation, J.P. (Jiwon Park) and H.C., investigation, J.P. (Jiwon Park) and H.C.; resources, J.P. (Jungsoo Park); 
writing—original draft preparation, J.P. (Jiwon Park); writing—review and editing, J.C. and J.P. (Jungsoo Park); supervision, J.P. (Jungsoo Park); funding acquisition, J.P. (Jungsoo Park). All authors have read and agreed to the published version of the manuscript.

Funding: This work was supported and funded by the Human Resources Program in Energy Technology of the Korea Institute of Energy Technology Evaluation and Planning (KETEP) and granted financial resources from the Ministry of Trade, Industry \& Energy (MOTIE, Korea) of the Republic of Korea (No. 20194030202410). This work was also supported by the Korea Institute of Energy Technology Evaluation and Planning (KETEP) and the Ministry of Trade, Industry \& Energy (MOTIE) of the Republic of Korea (No. 20184010201650).

Conflicts of Interest: No conflict of interests.

\section{Abbreviations}

\begin{tabular}{|c|c|}
\hline ANN & Artificial neural network \\
\hline ATDC & After top dead center \\
\hline BSNOx & Brake specific NOx emission \\
\hline BSFC & Brake specific fuel consumption \\
\hline $\mathrm{C}$ & Carbon \\
\hline CLD & Chemiluminescence detector \\
\hline $\mathrm{CO}$ & Carbon monoxide \\
\hline $\mathrm{CO}_{2}$ & Carbon dioxide \\
\hline DPF & Diesel particulate filter \\
\hline EGR & Exhaust gas recirculation \\
\hline FID & Flame ionization detector \\
\hline GC & Gas chromatography \\
\hline GHSV & Gas hourly space velocity \\
\hline $\mathrm{H}_{2}$ & Hydrogen \\
\hline $\mathrm{H}_{2} \mathrm{O}$ & Water vapor \\
\hline $\mathrm{LHV}_{\mathrm{H} 2}$ & Lower heating value of hydrogen \\
\hline $\mathrm{LHV}_{\text {Diesel }}$ & Lower heating value of diesel \\
\hline LP EGR & Low pressure exhaust gas recirculation \\
\hline $\mathrm{N}$ & Nitrogen atom \\
\hline $\mathrm{N}_{2}$ & Nitrogen molecule \\
\hline NDIR & Non dispersive infrared \\
\hline $\mathrm{NO}$ & Nitric Oxide \\
\hline NOx & Nitrogen Oxides \\
\hline $\mathrm{OH}$ & Hydroxide peroxyl \\
\hline $\mathrm{O}_{2}$ & Oxygen molecule \\
\hline$P_{\max }$ & Maximum pressure in cylinder \\
\hline SCR & Selective catalytic reduction \\
\hline THC & Total hydrocarbon \\
\hline $\mathrm{T}_{\text {exh }}$ & Exhaust gas temperature \\
\hline V & Volume \\
\hline
\end{tabular}

\section{References}

1. Heywood, J.; MacKenzie, D. On the Road toward 2050: Potential for Substantial Reductions in Light-Duty Vehicle Energy Use and Greenhouse Gas Emissions; MIT Energy Initiative Report: Cambridge, MA, USA, 2015.

2. Park, J.; Song, S.; Lee, K.S. Numerical investigation of a dual-loop EGR split strategy using a split index and multi-objective Pareto optimization. Appl. Energy 2015, 142, 21-32. [CrossRef]

3. Thangaraja, J.; Kannan, C. Effect of exhaust gas recirculation on advanced diesel combustion and alternate fuels-A review. Appl. Energy 2016, 180, 169-184. [CrossRef]

4. Singh, A.; Agrawal, M. Acid rain and its ecological consequences. J. Environ. Biol. 2008, 29, 15-24. [PubMed]

5. Cho, Y.; Song, S.; Chun, K.M. $\mathrm{H}_{2}$ effects on diesel combustion and emissions with an LPL-EGR system. Int. J. Hydrogen Energy 2013, 38, 9897-9906. [CrossRef]

6. Mohankumar, S.; Senthilkumar, P. Particulate matter formation and its control methodologies for diesel engine: A comprehensive review. Renew. Sustain. Energy Rev. 2017, 80, 1227-1238. [CrossRef] 
7. Kang, W.; Choi, B.; Jung, S.; Park, S. PM and NOx reduction characteristics of LNT/DPF+SCR/DPF hybrid system. Energy 2018, 143, 439-447. [CrossRef]

8. Heywood, J.B. Internal Combustion Engine Fundamentals; McGraw-Hill: New York, NY, USA, 1988.

9. Turns, R. An Introduction to Combustion; McGraw-Hill: New York, NY, USA, 1996.

10. Koebel, M.; Elsener, M.; Kleemann, M. Urea-SCR: A promising technique to reduce NOx emissions from automotive diesel engines. Catal. Today 2000, 59, 335-345. [CrossRef]

11. García, A.; Monsalve-Serrano, J.; Sari, R.; Dimitrakopoulos, N.; Tunér, M.; Tunestål, P. Performance and emissions of a series hybrid vehicle powered by a gasoline partially premixed combustion engine. Appl. Therm. Eng. 2019, 150, 564-575. [CrossRef]

12. Oğuz, H.; Sarıtas, I.; Baydan, H.E. Prediction of diesel engine performance using biofuels with artificial neural network. Expert Syst. Appl. 2010, 37, 6579-6586. [CrossRef]

13. Feng, S. Numerical Study of the Performance and Emission of a Diesel-Syngas Dual Fuel Engine. Math. Probl. Eng. 2017, 21,1-12. [CrossRef]

14. Tsolakis, A.; Torbati, R.; Megaritis, A.; Abu-Jrai, A. Low-Load Dual-Fuel Compression Ignition (CI) Engine Operation with an On-Board Reformer and a Diesel Oxidation Catalyst: Effects on Engine Performance and Emissions. Energy Fuels 2010, 24, 302-308. [CrossRef]

15. Cho, Y.; Song, S.; Chun, K.M. Effects of $\mathrm{H}_{2}$ on the number concentration of particulate matter in diesel engines using a low-pressure loop exhaust-gas recirculation system. Int. J. Hydrogen Energy 2014, 39, 6746-6752. [CrossRef]

16. Shin, B.; Cho, Y.; Han, D.; Song, S.; Chun, K.M. Investigation of the effects of hydrogen on cylinder pressure in a split-injection diesel engine at heavy EGR. Int. J. Hydrogen Energy 2011, 36, 13158-13170. [CrossRef]

17. Sher, I.; Sher, E. A novel internal combustion engine utilizing internal hydrogen production for improved efficiency-A theoretical concept. Int. J. Hydrogen Energy 2014, 39, 19182-19186. [CrossRef]

18. Chen, H.; Wang, X.; Pan, Z.; Xu, H. Numerical Simulation and Experimental Investigation of Diesel Fuel Reforming over a Pt/CeO $\mathrm{Cl}_{2}-\mathrm{Al}_{3}$ Catalyst. Energies 2019, 12, 1056. [CrossRef]

19. Tsolakis, A.; Megaritis, A. Partially premixed charge compression ignition engine with on-board production by exhaust gas fuel reforming of diesel and biodiesel. Int. J. Hydrogen Energy 2005, 30, 731-745. [CrossRef]

20. Jeon, M.; Noh, Y.; Shin, Y.; Lim, O.-K.; Lee, I.; Cho, D. Prediction of ship fuel consumption by using an artificial neural network. J. Mech. Sci. Technol. 2018, 32, 5785-5796. [CrossRef]

21. Li, H.; Butts, K.; Zaseck, K.; Liao-McPherson, D.; Kolmanovsky, I. Emissions Modeling of a Light-Duty Diesel Engine for Model-Based Control Design Using Multi-Layer Perceptron Neural Networks. SAE Technical Paper Series 2017, 1. [CrossRef]

22. De Cesare, M.; Covassin, F. Neural Network Based Models for Virtual NOx Sensing of Compression Ignition Engines; SAE Technical Paper No. 2011-24-0157; SAE: Troy, MI, USA, 2011.

23. Chen, H.; Wang, X.; Pan, Z.; Xu, H. Numerical Simulation and Experimental Study on Commercial Diesel Reforming Over an Advanced Pt/Rh Three-Way Catalyst. Catal. 2019, 9, 590. [CrossRef]

24. Kang, I. Atomization Effects of Diesel on Autothermal Reforming Reaction. J. ILASS Korea 2006, 11, $234-243$.

25. Tsolakis, A. Catalytic exhaust gas fuel reforming for diesel engines? Effects of water addition on hydrogen production and fuel conversion efficiency. Int. J. Hydrogen Energy 2004, 29, 1409-1419. [CrossRef]

26. Wan, M.N.C.; Mamat, R. Comparative study of artificial neural network and mathematical model on marine diesel engine performance prediction. IJICIC 2018, 14, 1349-4198.

Publisher's Note: MDPI stays neutral with regard to jurisdictional claims in published maps and institutional affiliations.

(C) 2020 by the authors. Licensee MDPI, Basel, Switzerland. This article is an open access article distributed under the terms and conditions of the Creative Commons Attribution (CC BY) license (http://creativecommons.org/licenses/by/4.0/). 